\title{
Energia Eólica e ODS: uma análise dos níveis de evidenciação socioambiental no Rio Grande do Norte/Brasil
}

\author{
Carla Montefusco ${ }^{1}$ \\ Maria João Santos ${ }^{2}$ \\ Joselma Ramos Carvalho Santos ${ }^{3}$
}

\begin{abstract}
RESUMO
O conceito para Responsabilidade Social Empresarial (RSE) envolve um conjunto de elementos que perpassam a natureza regional, cultural e as especificidades dos processos produtivos. Considerando a transparência como um dos pilares da RSE, a pesquisa ora apresentada objetivou analisar os níveis de evidenciação de RSE adotados pelas empresas de energia eólica instaladas no Rio Grande do Norte. Buscou-se, em particular, analisar de que forma as ações identificadas se aproximam das determinações propostas pela agenda 2030, relativa aos Objetivos do Desenvolvimento Sustentável (ODS). Ter por recorte amostral as corporações de energia eólica se justifica pela expansão desse segmento econômico no solo potiguar. Os procedimentos metodológicos utilizados para este trabalho consistem em revisão de literatura, bem como em pesquisa documental. Para fins de coleta dos dados, foram investigados os relatórios de sustentabilidade e materiais disponibilizados no websites das empresas. Dos 14 grupos empresariais identificados como responsáveis pelos 134 parques instalados no RN (2018), nove disponibilizam relatórios de sustentabilidade. Os relatórios identificados fazem menção aos ODS. No entanto, apenas três dos relatórios analisados explicitam especificamente ações sociais e ambientais desenvolvidas no âmbito do Rio Grande do Norte. Defende-se a relevância de maior explicitação das ações realizadas pelas empresas nos territórios locais para favorecer o acompanhamento stakeholders e o desenvolvimento de práticas que contemplem as efetivas necessidades de cada contexto social.
\end{abstract}

Palavras-Chave: energia eólica; evidenciação socioambiental; ODS, Rio Grande do Norte.

\author{
WIND ENERGY AND SDGs: an analysis of the levels of \\ socio-environmental evidence in Rio Grande do Norte/Brazil
}

\begin{abstract}
The concept for Corporate Social Responsibility (CSR) involves a set of elements that permeate the regional nature, cultural and specificities of production processes. Considering transparency as one of CSR pillars, the research presented here aimed to analyze CSR evidence levels adopted by wind energy companies installed in Rio Grande do Norte. We search, in particular, to analyze how the identified actions are close to the determinations proposed by the 2030 agenda, related to Sustainable Development Goals (SDGs). Having as sample cut the wind energy corporations is justified by the expansion of this economic segment in Potiguar territory. The methodological procedures used for this study consist of literature review, as well as documentary research. For data collection, were investigated sustainability report and available material on the companies' websites. Of the 14 business groups identified as responsible for the 134 parks installed in RN (2018), nine make sustainability reports available. The identified reports mention the SDGs. However, only three of the analyzed reports specifically explain social and environmental actions developed in Rio Grande do Norte. It is defended the relevance of greater explanation about actions taken by companies in local territories to favor the stakeholders monitoring and the practices development that contemplates the effective needs of each social context.
\end{abstract}

Keywords: wind energy; social and environmental disclosure; SDG, Rio Grande do Norte.

\footnotetext{
${ }^{1}$ Assistente Social. Doutora em Ciências Sociais. Professora Associada do Departamento de Serviço Social e do Programa de Pós-Graduação em Serviço Social da UFRN. Realizou Pós-doutoramento no ISEG/SOCIUS. carlamontefusco1@gmail.com

${ }^{2}$ Doutora em Sociologia Econômica e das Organizações, Professora Associada da Universidade de Lisboa com Agregação no Instituto Superior de Economia e Gestão da Universidade de Lisboa (ISEG-UL) e Investigadora Integrada do Centro de Investigação em Sociologia Econômica e das Organizações (SOCIUS-ISEG/UL). $\underline{\text { mjsantos@iseg.ulisboa.pt }}$

${ }^{3}$ Assistente Social pela UFRN. joselma.ramos@ymail.com
} 


\section{INTRODUÇÃO}

A energia renovável emerge, no circuito de produção de energia limpa, como uma estratégia alternativa às fontes convencionais de energia (combustíveis fósseis), contribuindo para diminuir o efeito de estufa e o aquecimento global, preservando ao mesmo tempo os recursos naturais do planeta. Em regiões suscetíveis de ter essas possibilidades, como o Brasil, otimizar esses recursos pode significar uma diminuição de impactos ambientais negativos.

O estado do Rio Grande do Norte, região Nordeste do Brasil, dispõe de uma situação geográfica privilegiada no tocante ao potencial eólico. Alem disto, tem sido crescentes as ações governamentais direcionadas a favorecer a instalação de negócios eólicos no estado. Como resultado do crescente interesse público e privado, tem havido uma expansão desse segmento econômico no solo potiguar. O estado é atualmente o primeiro do Brasil em termos da capacidade instalada em operação, com $3.617 .756 \mathrm{~kW}$ de potência outorgada; seguido pelo estado da Bahia, com 2.324.941 kW e pelo Ceará que se encontra em terceiro lugar, com 1.842.164 kW (ANEEL, 2018) ${ }^{4}$.

A energia eólica, apesar de ser considerada uma energia limpa, não está isenta de impactos ambientais e sociais negativos. $\mathrm{Na}$ fase de implantação da fonte energética eólica, por exemplo, os impactos ambientais mais recorrentes são o ruído, os efeitos visuais, a erosão e assoreamento, os materiais particulados, as interferências locais, bem como a supressão da vegetação, afugentamento da fauna local e prejuízo ao ciclo das aves migratórias já na fase de operação desse tipo de energia. Neste sentido, é relevante considerar os impactos associados ao desenvolvimento das organizações produtoras de energia eólica, investigar que ações são tomadas para mitigar os efeitos negativos e quais os mecanismos de gestão socialmente responsável utilizados.

A investigação realizada teve como objetivo analisar os níveis de evidenciação de RSE adotados pelas empresas de energia eólica instaladas no Rio Grande do Norte. Procurou-se, em particular, analisar de que forma as ações identificadas se aproximam das determinações propostas pela agenda 2030, relativa aos Objetivos do Desenvolvimento Sustentável (ODS). A investigação parte da premissa de que as ações RSE, internas ou externas, quando comunicadas aos diversos stakeholders de forma transparente, devem ter em consideração as necessidades locais e tendo subjacente a intenção de contribuir para patamares de desenvolvimento solicitados globalmente.

\footnotetext{
${ }^{4}$ Disponível: 〈http://www2.aneel.gov.br/aplicacoes/resumoestadual/resumoestadual.cfm〉. Acesso: 03 mar. 2018
} 
O estado do Rio Grande do Norte, com uma população de 3.306.853 habitantes, apresenta um IDH de 0,684. Do total populacional, 38\% da encontra-se abaixo da linha de pobreza, sendo que destes 10,3\% estão em condição de pobreza extrema (IBGE, 2019). Estes dados denotam que o estado, assim com os demais da região Nordeste, encontra-se entre os mais pobres do país, carecendo de políticas integradas e territorializadas que contribuam para o desenvolvimento socioeconômico da região. Deste modo, importa investigar de que forma as empresas eólicas instaladas no estado, no âmbito das ações RSE desenvolvidas, contribuem para o desenvolvimento local das comunidades onde se instalam.

Para além da introdução, o presente artigo apresenta, no item dois, a descrição do método de investigação utilizado na pesquisa. Em seguida, no item três, apresenta considerações sobre a produção de energia renovável na realidade mundial e brasileira e, mais especificamente, a de fonte eólica. No item quatro são debatidos os complexos organizativos de energia eólica no Rio Grande do Norte e o que essas empresas evidenciam acerca de responsabilidade socioambiental para o Estado. No quinto item são elencados, a partir da realidade investigada, os desafios postos ao alcance dos ODS. Por último, são tecidas as considerações finais.

\section{METODOLOGIA}

A investigação realizada tem cunho qualitativo e os procedimentos metodológicos consistiram em revisão bibliográfica e pesquisa documental. A coleta de dados foi realizada com base na análise dos relatórios de sustentabilidade e nos materiais disponibilizados nos websites das empresas, visto que, no Brasil, a NBR ISO 26000 (2010) estimula os recursos multimídias para divulgação de balanços sociais, relatórios socioambientais e dos próprios balanços financeiros pelas empresas. Os relatórios e demais materiais identificados foram analisados na integra, contudo, para fins deste estudo fez-se um recorte sobre as ações realizadas na realidade do Rio Grande do Norte, tendo em vista o objetivo da pesquisa.

O Disclosure Social, ou evidenciação social, como é conhecida a divulgação de um conjunto de informações sobre o envolvimento da empresa com a comunidade, funcionários, benefícios dos produtos oferecidos, ocorre no Brasil de forma voluntária, mas nem por isso a transparência nas divulgações pode ser negligenciada. Milani Filho (2008, p. 91) avalia que a simples divulgação empresarial de notícias nos websites sobre qualquer ação social ou 
ambiental sem a devida evidenciação dos fatos não comprova o comprometimento nem dimensiona as ações sociais da organização junto aos diferentes públicos.

A ausência de comportamento social normativo não pode transmutar para divulgações deliberativas que não sejam muito claras, além disso, conforme explicam Pinto e Ribeiro (2005, p. 36-37),

[...] a divulgação das ações sociais das organizações, dos planos internos voltados ao seu ativo humano, das políticas de investimentos direcionadas ao meio ambiente, da evidenciação da formação e distribuição da riqueza e contribuições a entidades assistenciais é de grande utilidade não somente para o público, mas também para a própria organização que as publica, haja vista que a publicação do Balanço Social, elaborado com informações fidedignas, é um instrumento que propicia um relacionamento mais íntimo com o público e, consequentemente, a melhoria de imagem da empresa, além de servir como instrumento de controle e avaliação aos gestores.

Utilizou-se para seleção da amostra o site da Agência Nacional de Energia Elétrica ANEEL que alimenta o Banco de Informações de Gerações - BIG $^{5}$ e torna públicas as informações concernentes a todos os empreendimentos de geração de energia do país, considerando a localização (estados e municípios), o quantitativo de usinas, a potência $(\mathrm{kW})$ outorgada e fiscalizada ${ }^{6}$ de cada uma, bem como a data do início da operação e os proprietários dessas usinas. Explica-se, no entanto, que tendo em vista o direcionamento da pesquisa resguardou-se exposição dos nomes das organizações, embora todos os dados observados sejam públicos e estejam disponibilizados em diversos meios de comunicação.

$\mathrm{O}$ enquadramento analítico do material coletado seu deu a partir da busca por alguns descritores das práticas socioambientais realizadas no Rio Grande do Norte, quais sejam: o envolvimento da empresa com os stakeholders; a política de governança; os compromissos socioambientais assumidos pela empresa nas localidades em que se instalam e os impactos das ações de RSE realizadas.

\section{ENERGIA EÓLICA: A ESPECIFICIDADE BRASILEIRA}

É a partir da década de 1970, com a crise energética ocasionada pelos aumentos sucessivos no preço do petróleo - o choque do petróleo - que internacionalmente se aborda a questão da revisão da matriz energética vigente e se começa a propor alternativas aos combustíveis fósseis. A Agência Internacional de Energia (International Energy Agency),

\footnotetext{
5 A amostra foi definida no período compreendido entre novembro de 2017 e janeiro de 2018. Qualquer organização inclusa no BIG após este período não compõem a amostra deste estudo.

${ }^{6}$ Segundo a ANEEL a Potência Outorgada é igual à considerada no Ato de Outorga, enquanto a Potência Fiscalizada é igual a considerada a partir da operação comercial da primeira unidade geradora.
} 
criada em 1974, em consonância com a Organização para Cooperação e Desenvolvimento Econômico (OCDE), apresentou diretivas junto aos países membros no sentido da redução do consumo de petróleo.

As diretivas da IEA convergiram no sentido do uso mais disciplinado do petróleo. Foram orientações de incentivo à diversificação das fontes de importação do petróleo, substituição do petróleo por outras fontes de energia e maior racionalidade na utilização da energia de forma que o fornecimento do produto não fosse abalado e as reservas petrolíferas dos Estados signatários fossem garantidas e mantidas em segurança (FADIGAS, 2011; SILVA, 2017). Países como Estados Unidos, Dinamarca, Alemanha, concentraram estudos e pesquisas sobre novas configurações que pudessem ser incorporadas nesse segmento energético no aprimoramento das funções. Em 1976 a Dinamarca instalou a primeira turbina eólica comercial ligada à rede elétrica pública. A partir dessas experiências de estímulo ao mercado, a energia eólica como alternativa de geração de energia elétrica limpa atingiu escala de contribuição mais significativa ao sistema elétrico (RUNCOS et al ,2000).

Foi justamente com financiamento de um instituto de pesquisa dinamarquês, o Folkecenter, em parceria com a Companhia Energética de Pernambuco - CELPE, que foi instalada em Fernando de Noronha - PE, a primeira turbina de energia eólica do Brasil. No entanto, é a partir da crise de abastecimento do setor elétrico nacional, no início dos anos 2000, que se vê maiores avanços no debate em torno da produção de energia limpa no cenário brasileiro.

A partir dessa crise de abastecimento do setor elétrico, concretizada no primeiro semestre de 2001, o governo do Brasil instituiu a Câmara de - Gestão da Crise de Energia Elétrica - GCE. A referida Câmara, com o intuito de promover o aproveitamento da energia eólica como alternativa ao desenvolvimento energético, econômico, social e ambiental cria o Programa de Incentivo às Fontes Alternativas de Energia Elétrica - Proinfa (OLIVEIRA et al, 2015).

Os incentivos à energia renovável instituídos pelo Proinfa previram uma quota de energia para cada uma das fontes (eólica, PCH e biomassa), bem como o estabelecimento de leilões para geração de médio porte e o incentivo por parte do governo no oferecimento de linhas especiais de crédito do Banco Nacional do Desenvolvimento (BNDES) (OLIVEIRA et al, 2015; FERREIRA, 2011).

As precedentes manifestações sobre o comportamento social no uso dos recursos socioambientais influenciaram o Brasil em direção a uma responsabilidade sustentável, 
fazendo-o corroborar o pensamento de que a mudança do clima da Terra e seus efeitos negativos precisam ser uma preocupação comum de toda a humanidade (FERREIRA, 2011). Entretanto, o país ainda tem um perfil poluidor. Segundo o IEMA (2015), análises realizadas no Brasil sobre a primeira versão do Sistema de Estimativa de Emissões de Gases de Efeito Estufa (SEEG) verificaram que as emissões partiram de um patamar de 220,8 milhões de toneladas de dióxido de carbono equivalente (CO2 e) em 1990, para 449,3 milhões de toneladas em 2013, validando o pensamento de que "a posição brasileira na política global, reconhecida tradicionalmente como proativa, muitas vezes não se transformou em ações internas que guardassem coerência com a projeção externa em relação a temas ambientais e climáticos” (FERREIRA, 2011, p. 83).

Ainda assim, não se nega o incentivo ao uso mais diversificado de fontes renováveis para a produção de energia elétrica. A inserção da energia renovável no país, mesmo que tenha sido impulsionada pelos problemas energéticos internos que ocorreram na década de 2000, tem se consubstanciado como medida mitigadora dos impactos ambientais.

Apesar disso, os combustíveis fósseis ainda são amplamente utilizados no mundo. No ano de 2012 essas fontes contribuíram para a geração de 67,3\% da energia elétrica produzida no mundo (BRASIL, 2016), embora cada vez mais seu uso tem sido rejeitado pelos ambientalistas. Além disso, são recursos considerados finitos, já que a natureza não tem como renovar essas fontes em esfera de tempo necessário ao seu uso pelos homens (GOLDENBERG; LUCON, 2008).

A busca de alternativas requer a adoção conjunta de medidas que devem ser retificadas pelas nações, pois que "o caráter transnacional dos desafios ambientais significa também que nenhum país está imune às suas consequências, ainda quando não tenha um papel protagonista na gênese destes [...]" (FERREIRA, 2011, p. 83).

No Brasil, o Conselho Nacional do Meio Ambiente (CONAMA) (órgão criado em 1982 pela Lei ${ }^{\circ}$ 6.938/81 que estabelece a Política Nacional do Meio Ambiente) exige que qualquer uma das fontes primárias que seja instalada no território nacional, tem de ter particular atenção aos locais onde as empresas se pretendem instalar. No caso específico dos empreendimentos eólicos, estes devem: nas formações dunares, considerar as planícies fluviais e de deflação, mangues e demais áreas úmidas; no bioma Mata Atlântica, evitar o corte e supressão de vegetação primária e secundária no estágio avançado de regeneração; na Zona Costeira, garantir que não ocorram alterações significativas das características naturais; dentre tantos outras requisitos (BRASIL, 1986). 
O fortalecimento do setor eólico no Brasil resulta também de alguns outros marcos, como, por exemplo, a primeira edição do Fórum Nacional Eólico (Carta dos Ventos), que aconteceu em Natal/RN, no ano de 2009. Nesse momento, entidades diversas assinaram um documento de responsabilidade com o setor concentrando objetivos e definição de atribuições de cada representante, tratando-se do Fórum Nacional de Secretários de Estado para Assuntos de Energia e os Ministério de Minas e Energia (MME), do Ministério do Meio Ambiente (MMA), da Associação Brasileira de Energia Eólica (ABEEÓLICA) e Poderes Legislativos Federal e Estadual, havendo o incentivo para o acompanhamento integrado do processo de realização do leilão.

Segundo o Global Wind Energy Council - GWEC (2017), em 2016, das dez capacidades instaladas no mundo coube ao Brasil a quinta posição, sendo o nono país com capacidade de potência do vento instalada, com 10,74 MW de capacidade. A central geradora eólica é a terceira fonte de geração de energia em operação no Brasil, com capacidade de 12.532.539 kW em potência outorgada e 510 empreendimentos em operação (a primeira é a hidrelétrica, com $101.883 .450 \mathrm{~kW}$ de capacidade e 218 empreendimentos, e a termelétrica assume a segunda colocação em geração, com 42.703.115 kW e 2.999 empreendimentos) (ANEEL/BIG, 2018) ${ }^{7}$.

\section{UMA ANÁliSE DO NÍVEL DE EVIDENCIAÇÃO SOCIOAMBIENTAL DAS EMPRESAS EÓLICAS}

Segundo a ANEEL $(2018)^{8}$, o Rio Grande do Norte concentra 134 empreendimentos eólicos em operação, o que equivale a uma potência total de 3.617 .756 kW . Convém ressaltar diante dessa expansão, que o fato da energia eólica se destacar como limpa, não implica afirmar que a instalação das usinas se dará sem impactos ambientais. Já que se entende por impacto ambiental, segundo resolução do CONAMA nº 001/1986 (BRASIL, 1986),

Qualquer alteração das propriedades físicas, químicas e biológicas do meio ambiente, causada por qualquer forma de matéria ou energia resultante das atividades humanas que, direta ou indiretamente, afetam:

I - a saúde, a segurança e o bem-estar da população;

II - as atividades sociais e econômicas;

III - a biota;

IV - as condições estéticas e sanitárias do meio ambiente;

$\mathrm{V}$ - a qualidade dos recursos ambientais.

\footnotetext{
${ }^{7}$ Verificação realizada no dia 06 de março de 2018.

${ }^{8}$ Dados constantemente atualizados em https://www.aneel.gov.br/
} 
Quanto ao licenciamento ambiental de empreendimentos de geração de energia elétrica a partir de fonte eólica, a Resolução CONAMA nº 462/2014 (BRASIL, 2014) disciplina sobre estabelecimentos em superfície terrestre, quer seja usina eólica singular (unidade aerogeradora, formada por turbina eólica, geradora de energia elétrica); parque eólico (conjunto de unidades aerogeradoras); ou complexo eólico (conjunto de parques eólicos) fazendo ressalva de que cabe ao órgão licenciador o enquadramento quanto ao impacto ambiental desses empreendimentos considerando o porte, a localização e o baixo potencial poluidor da atividade.

No segmento econômico eólico no Rio Grande do Norte são comuns as configurações por conglomerados que não se restringem a uma única fonte de produção ou a uma mesma atividade econômica, nem também a uma região ou país. As organizações se relacionam em condição de subsidiárias, controladas, coligadas, controladas em conjunto, ou mesmo por consórcio de empresas. No referido modo organizativo, os parques eólicos se acomodam por complexos, sendo isso agrupamentos de várias usinas que se vinculam às organizações.

As análises do $\mathrm{BIG}^{9}$ possibilitaram a informação de que o Rio Grande do Norte tem em operação um expressivo número de 134 usinas eólicas distribuídas por 20 municípios, os quais são: Rio do Fogo, Guamaré, Macau, Parazinho, João Câmara, Areia Branca, São Bento do Norte, Bodó, Pedra Grande, Brejinho, São Miguel do Gostoso, Lagoa Nova, Touros, Ceará Mirim, Serra do Mel, Jandaíra, Santana dos Matos, Cerro Corá, Tenente Laurentino Cruz e Galinhos.

Foram identificadas pela pesquisa 14 organizações que, em alguma medida, são responsáveis por quase a totalidade ${ }^{10}$ dos complexos e parques eólicos, já que estes podem ser controlados ou subsidiados por outras empresas. Desses grupos, foram identificados 09 relatórios de sustentabilidade ${ }^{11}$ que apresentam planejamentos, ações e projetos de cunho socialmente responsável, incluindo iniciativas de investimento social privado. Todos os relatórios identificados incorporam itens da normatização do Global Reporting Initiative (GRI), bem como fazem menção aos ODS em suas diretrizes.

\footnotetext{
9 Tendo em vista que o BIG/ANEEL sofre atualização constante, torna-se importante esclarecer que todas as informações sobre capacidade instalada, total de usinas, potência outorgada, conferem com análises realizadas no dia 03 de março de 2018. Disponível em:

<http://www2.aneel.gov.br/aplicacoes/resumoestadual/resumoestadual.cfm>. Acesso em: 03 mar. 2018.

${ }^{10}$ Explica-se que em razão da própria dinâmica organizativa, a pesquisa não inferiu a coligação de todos os parques, ou seja, não identificou no recorte amostral a sociedade controladora de $25 \%$ dos parques.

${ }^{11}$ Dado o período da investigação, os relatórios analisados referem-se ao no de 2016.
} 
Quadro 1 - Panorama da Evidenciação Socioambiental nas Empresas Pesquisadas

\begin{tabular}{|c|c|c|c|}
\hline Empresas & Divulgam Relatório & $\begin{array}{c}\text { Há evidenciação de } \\
\text { ações de RSE no RN }\end{array}$ & $\begin{array}{c}\text { Explicita ações de RSE realizadas } \\
\text { no RN no Website }\end{array}$ \\
\hline G1 & Sim & Não & Não \\
\hline G2 & Sim & Não & Não \\
\hline G3 & Sim & Não & Não \\
\hline G4 & Sim & Não & Não \\
\hline G5 & Sim & Sim & Não \\
\hline G6 & Sim & Não & Sim \\
\hline G7 & Não & Não & Sim \\
\hline G8 & Não & Não & Sim \\
\hline G9 & Não & Não & Sim \\
\hline G10 & Não & Não & Não \\
\hline G11 & Sim & Sim & Não \\
\hline G12 & Sim & Sim & Sim \\
\hline G13 & Sim & Não & Não \\
\hline G14 & Não & Não & \\
\hline
\end{tabular}

Fonte: Coleta direta de dados, 2017

Os nove relatórios identificados demonstram ações educativas e socioculturais realizadas com recursos próprios e incentivos fiscais, investimentos em Fundos Municipais de Direitos da Criança e do Adolescente; ações educacionais voltadas para o ingresso de jovens moradores de abrigos no mercado de trabalho; escola inclusiva; festival literário; investimentos em cultura, proteção ambiental e no esporte; ações com as comunidades; políticas para a área de segurança, meio ambiente, saúde e recursos hídricos, habitação, redução tarifária de energia; campanha de vestimentas para doação a lares espíritas, cristãos, e a casas de apoio a crianças com câncer; pesquisa e desenvolvimento; programa de eficiência energética, promoção da cidadania e dos direitos, geração de trabalho e renda.

Estes 9 relatórios identificados também evidenciam a política de governança das empresas, bem como as diretrizes gerais de sustentabilidade que devem ser incorporadas por todas as filiais. O total dos relatórios também apresenta, em formatos quantitativos ou qualitativos, os impactos das ações de RSE desenvolvidas. No entanto, destes relatórios identificados apenas 03 fazem referência à prática de RSE voltada para o Estado do Rio Grande do Norte especificamente, sendo que um destes apenas menciona montantes de investimentos nos parques instalados, não apresentando menção às dimensões social e ambiental.

Apesar dos relatórios incorporarem diretrizes do GRI, não há uniformidade na elaboração dos mesmos. Alem disto, observa-se, no referente à especificidade do Rio Grande do Norte, uma generalidade na divulgação de algumas ações e um baixo nível de evidenciação no referente aos stakeholders efetivamente beneficiados pelas ações. Não é possível 
identificar pelos indicadores dispostos nos relatórios os impactos esperados das ações socioambientais desenvolvidas no Rio Grande do Norte, nem tampouco os mecanismos de materialização das diretrizes de governança e sustentabilidade divulgadas pelas empresas.

Importa ressaltar, contudo, que, nos três relatórios analisados é possível identificar projetos direcionados mais diretamente a outros Estados brasileiros, a saber: Paraná, Rio de Janeiro, Espírito Santo, Minas Gerais, Mato Grosso, Goiás, São Paulo, Bahia, sendo citados até mesmo comunidades e municípios. Possivelmente a operação das empresas nestes Estados já tenha um histórico mais longo o que possibilitou estabelecer relações mais interconectadas às demandas dos stakeholders locais.

Importante ressaltar que para além dos três relatórios que citam o estado do Rio Grande do Norte, cinco outros grupos, por meio de seus websites, demonstram prática de RSE voltadas para o estado em abas das páginas de web que evidenciam notícias e projetos no campo da sustentabilidade. Dentre estas ações para o Rio Grande do Norte identificam-se projetos de segurança hídrica para comunidades de João Câmara e São Miguel do Gostoso (RN); desenvolvimento integrado e sustentável da cadeia produtiva da apicultura na região do Mato Grande/RN; troca de resíduos sólidos (metal, papel, papelão e plásticos) por descontos na conta de energia de clientes residenciais e geração de energia e eficiência energética.

São evidenciados ainda projetos realizados no Parazinho e João Câmara (construção de um clube para idosos e apoio na formação de uma brinquedoteca no Centro de Referência de Assistência Social (CRAS), convênio com a polícia militar no aparelhamento para execução dos serviços de policiamento, em parceria com os governos locais); formação de guias mirins; monitoramento das desovas das tartarugas em Macau e Guamaré; ações educativas e de incentivo cultural à comunidade; projeto de incentivo ao saneamento básico objetivando o tratamento de redes de esgotos de forma ecológica em João Câmara; ações conjuntas com instituições público-privadas para a capacitação de pessoas em diversas especialidades; geração de empregos diretos e indiretos em Macau e Guamaré.

Os materiais identificados por meio dos websites das cinco empresas que mencionam o Rio Grande do Norte denotam que a RSE está na agenda empresarial. No entanto, como as ações são apresentadas fora dos padrões dos relatórios, é possível identificá-las em um panorama mais geral, sem, no entanto, identificar parâmetros que permitam um alinhamento com os descritores selecionados para investigação.

A partir dos materiais evidenciados pelas organizações componentes da amostra é possível inferir que as empresas eólicas no Rio Grande do Norte estão utilizando a perspectiva 
de Zadek (2004), entre os estágios compliance e managerial. Pelas ações analisadas percebese uma preocupação em proteger a reputação das empresas, garantindo legitimidade aos negócios, bem como o gerenciamento de problemas centrais dos negócios, tais como os impactos ambientais. Entretanto, ainda não se identifica uma relação mais estreita das ações de RSE com as necessidades mais específicas do território do Rio Grande do Norte, o que era o objetivo analítico central desta investigação, considerando a relevância de mensuras os impactos sociais e ambientais das empresas nas especificidades locais dos territórios.

O avanço no comportamento empresarial socialmente responsável exige a compreensão de que a responsabilidade social não é uma "prática limitada a projetos específicos, precisa ser fomentado num espectro mais amplo, permeando toda a organização, incorporando a performance social corporativa (ZAMBOIN, 2006, p. 385). É fundamental que se fortaleçam os movimentos de incentivo e cobrança, tanto por partes dos governos quando da sociedade civil, por práticas empresariais socialmente responsáveis que se alinhem às demandas locais de desenvolvimento das regiões, bem como aos ODS.

\section{TRANSPARÊNCIA EMPRESARIAL E ODS: DESAFIOS POSTOS A PARTIR DA REALIDADE INVESTIGADA}

Em 2015, a Organização das Nações Unidas - ONU definiu uma agenda, para o intervalo de 15 anos, com 17 Objetivos do Desenvolvimento Sustentável - ODS e 169 metas. A agenda é um plano de ação para pessoas, o planeta e a prosperidade. Os países signatários do documento, dentre eles o Brasil, e as partes interessadas devem atuar em parceria colaborativa no intuito de acabar com a pobreza, proteger o planeta e direcionar o mundo para um caminho sustentável (ODS, 2015).

A adesão aos ODS é, contemporaneamente, uma forma de as empresas, enquanto atores sociais partícipes do desenvolvimento, demonstrarem compromisso com a sustentabilidade. Contudo, para além da adesão formal, torna-se fundamental refletir acerca das ações que efetivamente as empresas vem desenvolvendo nos campos social e ambiental. Nessa direção, defende-se o princípio da transparência como central no entendimento do papel que as empresas têm assumido na incorporação dos dez princípios do Pacto Global, bem como diante dos ODS.

De acordo com a UN (2018), a ONU considera as empresas como parceiras essenciais para a consecução dos ODS. É essencial, então, que as empresas "(...) contribuam por meio de 
seus negócios principais, avaliando seus principais impactos, estabelecendo metas ambiciosas e comunicando seus resultados de forma transparente" (p.8).

Na realidade investigada observou-se que, de maneira geral, as empresas já demonstram preocupação com o papel que precisam desempenhar no que se refere à contribuição social e ambiental. No entanto, como $38 \%$ da população norteriogradense vive abaixo da linha da pobreza com acesso limitado à infraestrutura básica e de serviços, é fundamental que as empresas que se instalem no estado possam direcionar suas ações para as especificidades desta realidade. As ações de combate à pobreza, seja oriunda das políticas de Estado ou das práticas empresarias, devem considerar as particularidades da dinâmica econômica territorial, sejam elas urbanas ou rurais (Spinelli, 2014).

O SGD Compass (2015) define 5 passos integração dos ODS nas estratégias empresariais, quais sejam: compreensão dos ODS; definição de prioridades frente aos ODS; metas para aperfeiçoar a abordagem aos ODS; integração dos ODS ao negócio e estímulo à comunicação dos resultados e progressos na direção dos ODS. Tomando como partida estes passos, observa-se que o alinhamento das empresas aos ODS será mais eficiente quanto mais próximo estiver da definição de prioridades que estejam fortemente integradas às necessidades locais.

Os resultados positivos obtidos pelas empresas terão maior impacto efetivo se estiverem atendendo às carências locais, em especial quando se trata de regiões pauperizadas, como é o caso do Rio Grande do Norte. Além disso, a comunicação transparente destes resultados obtidos pode servir de base para a construção de estratégias coletivas entre empresas privadas e poder público.

A evolução da aproximação das práticas de RSE com os ODS depende de fatores que compõem o espaço social na qual estão inseridas. Classificar as empresas em mais próximas ou mais distantes da contribuição às metas estabelecidas pelos ODS, implica analisar os determinantes que medeiam as complexas relações entre empresa/territórios locais, pois "(...) a regulação mercantil não existe separada da regulação institucional nem das relações societais, sejam elas formais ou informais (REIS, 2004, p. 88).

A ambiência institucional pública, portanto, faz-se fundamental no processo de amadurecimento das práticas empresariais coadunadas aos ODS. Entretanto, no Brasil, de maneira geral, há ainda carência de organismos públicos que incorporem o controle mais efetivo sobre as práticas empresariais. 
O alcance dos ODS embasa pilares que sustentam o sucesso dos negócios, pois, dentre outros aspectos, retira bilhões de pessoas da condição de pobreza e permite que a economia opere em acordo com a capacidade do planeta de fornecer recursos essenciais (SGD Compass, 2015). Nessa direção, o investimento empresarial e público no desenvolvimento sustentado, referenciado nas dinâmicas e potencialidades locais, é essencial à melhoria da qualidade de vida das populações e ao crescimento dos negócios.

\section{CONSIDERAÇÕES FINAIS}

As organizações diversas que compõem o campo da produção de energia eólica no Rio Grande do Norte são também, por vezes, detentoras de outros negócios, em localizações geográficas diversas. Esse fato acaba contribuindo para que a comunicação das ações socioambientais ocorra de forma mais ampla, ficando secundarizado o detalhamento acerca dos impactos locais das ações. Uma hipótese, a ser investigada em estudos futuros, é que as empresas são relativamente novas no Estado do Rio Grande do Norte, e, portanto, ainda estão se enraizando na ambiência das necessidades locais.

Cabe ressaltar que, embora os níveis de divulgação das ações socioambientais voltadas diretamente ao Rio Grande do Norte tenham sido moderados na amostra pesquisada, a apresentação dos relatórios de sustentabilidade no modelo GRI e a disponibilização de materiais nos websites indicam uma preocupação importante que carece de avanços no tocante à relação mais direta das empresas com os stakeholders no Rio Grande do Norte.

Avalia-se, portanto, que o nível de evidenciação socioambiental das empresas analisada ainda é baixo, considerando também que os relatórios disponibilizados trazem informações genéricas que não destacam especificidades do Rio Grande do Norte. Defendese ser dever das empresas estabelecerem com mais clareza os mecanismos de divulgação transparente de suas ações nos territórios em que estão instaladas, favorecendo o acompanhamento dos stakeholders e o desenvolvimento de práticas que contemplem as efetivas necessidades de cada contexto social.

Importa destacar que a investigação ora relatada se concentrou na análise de materiais divulgados pelas empresas, considerando que a comunicação transparente é um pilar central da RSE e que a gestão socialmente responsável exige uma relação estreita com as especificidades locais. Contudo, aponta-se para a importância do exame de outras fontes de investigação, bem como de outros segmentos econômicos importantes no estado, para permitir 
o delineamento de um quadro analítico mais apurado acerca das condições sob as quais vem se efetivando a RSE no Rio Grande do Norte.

Por fim, considera-se o campo de estudos da RSE fecundo à compreensão das mediações e das contradições presentes na relação entre estado, empresa e sociedade. Apreender, portanto, os determinantes que compõem as tramas da RSE em uma dada região é, em larga medida, construir caminhos analíticos que permitam desvelar as perspectivas do desenvolvimento socioambiental na contemporaneidade e as possibilidades de construção de uma sociedade efetivamente mais justa e equânime, horizonte dos ODS.

\section{REFERÊNCIAS}

BRASIL. Conselho Nacional do Meio Ambiente. Resolução n ${ }^{\circ}$ 001, de 23 de janeiro de 1986. Dispõe sobre critérios básicos e diretrizes gerais para o Relatório de Impacto Ambiental - RIMA. Diário Oficial da República Federativa do Brasil, Brasília, DF, 17 fev. 1986.

BRASIL. Resolução CONAMA nº 462, de 24 de julho de 2014. Diário Oficial da República Federativa do Brasil, Poder Executivo, Brasília, DF, 25 jul. 2014.

BRASIL, Anuário de Energia Elétrica 2017 - ano base 2016. Disponível em: http://www.epe.gov.br/sites-pt/publicacoes-dadosabertos/publicacoes/PublicacoesArquivos/publicacao-160/topico-168/Anuario2017vf.pdf. Acesso em: 20 set 2017.

FADIGAS, Eliane A. F. A. Energia eólica. Barueri: Manole, 2011. (Série Sustentabilidade).

FERREIRA, L. da C. Qualidade de vida e risco na produção intelectual na área de ambiente e sociedade: algumas considerações. In:

Latina. Campinas: UNICAMP, 2011. p. 159-187.

Global Wind Energy Council - GWEC. Global Wind Statistics 2016. Disponível em: https://www.gwec.net/wp-content/uploads/vip/GWEC_PRstats2016_EN_WEB.pdf Acesso em: 13 out 2017

GOLDEMBERG, José; LUCON, Oswaldo. Energia, meio ambiente e desenvolvimento. São Paulo: EDUSP, 2008.

INSTITUTO BRASILEIRO DE GEOGRAFIA E ESTATÍSTICA - IBGE. Síntese de indicadores sociais : uma análise das condições de vida da população brasileira. Rio de Janeiro: IBGE, 2019.

INSTITUTO DE ENERGIA E MEIO AMBIENTE (IEMA). Documento de Análise: evolução das emissões de gases de efeito estufa no Brasil (1970-2013) setor de energia e processos industriais. São Paulo : Observatório do Clima, 2015. 
MILANI FILHO, M. A. F. Responsabilidade social e investimento social privado: entre o discurso e a evidenciação. Revista Contabilidade e Finanças - USP, São Paulo, v. 19, n.47, p.88-101, mai/ago , 2007.

OLIVEIRA, C.B.M. (et al). Guia do Setor Eólico do RN. Natal: IFRN, 2015.

ONU - ORGANIZAÇÃO DAS NAÇÕES UNIDAS. Objetivos do Desenvolvimento Sustentável, 2015. Disponível em https://nacoesunidas.org/wpcontent/uploads/2015/10/agenda2030-pt-br.pdf. Acesso em 03 de Abril de 2019.

PINTO, A. L.; RIBEIRO, M. de S. O Balanço Social como instrumento de evidenciação de responsabilidade social: um estudo no estado de Santa Catarina. Revista Brasileira de Contabilidade, [S.1.], n. 154, p. 34-47, jul./ago. 2005.

REIS, J. Estado e mercado: Uma perspetiva institucionalista e relacional. Revista Crítica de Ciências Sociais, 95, Dezembro 2011, p. 11-34

SDG Compass. Diretrizes para implementação dos ODS na estratégia dos negócios. 2015. Disponível em: https://sdgcompass.org/wp content/uploads/2016/04/SDG_Compass_Portuguese.pdf. Acesso 20 Abr 2020.

SILVA, M. das G. Capitalismo contemporâneo e questão ambiental: o desenvolvimento sustentável e a ação do Serviço Social. 2008. 210 f. Tese (Doutorado)-Universidade Federal de Pernambuco, Recife, 2008.

SPINELli, J. a. (org.). Rio Grande do Norte 2000-2013. São Paulo : Editora Fundação Perseu Abramo, 2014.

UN. Rede Brasil do Pacto Global e Capítulo Brasileiro dos Princípios para Educação Empresarial Responsável. Contribuições da Rede Brasil do Pacto Global para a Agenda 2030, 2018.

ZADEK, S. The Path to Corporate Responsibility. Harvard Business Review. December, 2004, 82, 12, pp. 125-132.

ZAMBOIN, Maurício Eugênio. A avaliação como instrumento de gestão em projetos de responsabilidade social empresarial. Prêmio ETHOS Valor, v.5, São Paulo:

Peirópolis/Instituto ETHOS, 2006. 